\title{
A Brief Outline of the Use of New Technologies for Treating Substance Use Disorders in the European Union
}

Citation for published version (APA):

Quaglio, G., Schellekens, A., Blankers, M., Hoch, E., Karapiperis, T., Esposito, G., Brand, H., Nutt, D., \& Kiefer, F. (2017). A Brief Outline of the Use of New Technologies for Treating Substance Use Disorders in the European Union. European Addiction Research, 23(4), 177-181. https://doi.org/10.1159/000478904

Document status and date:

Published: 01/10/2017

DOI:

10.1159/000478904

Document Version:

Publisher's PDF, also known as Version of record

Document license:

Taverne

Please check the document version of this publication:

- A submitted manuscript is the version of the article upon submission and before peer-review. There can be important differences between the submitted version and the official published version of record.

People interested in the research are advised to contact the author for the final version of the publication, or visit the DOI to the publisher's website.

- The final author version and the galley proof are versions of the publication after peer review.

- The final published version features the final layout of the paper including the volume, issue and page numbers.

Link to publication

\footnotetext{
General rights rights.

- You may freely distribute the URL identifying the publication in the public portal. please follow below link for the End User Agreement:

www.umlib.nl/taverne-license

Take down policy

If you believe that this document breaches copyright please contact us at:

repository@maastrichtuniversity.nl

providing details and we will investigate your claim.
}

Copyright and moral rights for the publications made accessible in the public portal are retained by the authors and/or other copyright owners and it is a condition of accessing publications that users recognise and abide by the legal requirements associated with these

- Users may download and print one copy of any publication from the public portal for the purpose of private study or research.

- You may not further distribute the material or use it for any profit-making activity or commercial gain

If the publication is distributed under the terms of Article $25 \mathrm{fa}$ of the Dutch Copyright Act, indicated by the "Taverne" license above, 


\title{
A Brief Outline of the Use of New Technologies for Treating Substance Use Disorders in the European Union
}

\author{
GianLuca Quaglio ${ }^{\mathrm{a}} \mathrm{h}$ Arnt Schellekens ${ }^{\mathrm{b}}$ Matthijs Blankers ${ }^{\mathrm{c}-\mathrm{e}}$ Eva Hoch ${ }^{f}$ \\ Theodoros Karapiperis $^{\text {a }}$ Giovanni Esposito $^{g}$ Helmut Brand ${ }^{\text {h }}$ David Nutt ${ }^{g}$, i \\ Falk Kiefer ${ }^{j}$ \\ ${ }^{a}$ Scientific Foresight Unit (Science and Technology Options Assessment [STOA]), Directorate-General for \\ Parliamentary Research Services (EPRS), European Parliament, Brussels, Belgium; ${ }^{b}$ Radboud University Medical \\ Centre, Donders Institute for Brain, Cognition and Behaviour, Nijmegen Institute for Scientists Practitioners in \\ Addiction, Nijmegen, The Netherlands; ${ }^{\mathrm{C}}$ Trimbos Institute - The Netherlands Institute of Mental Health and \\ Addiction, Utrecht, ${ }^{d}$ Arkin Mental Health Care, and ${ }^{~}$ Department of Psychiatry, Academic Medical Centre, University \\ of Amsterdam, Amsterdam, The Netherlands; ${ }^{\mathrm{f}}$ Department of Psychiatry, Ludwig Maximilian University, Munich,

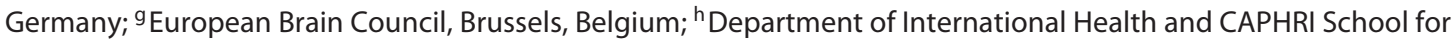 \\ Public Health and Primary Care, University of Maastricht, Maastricht, The Netherlands; 'Imperial College London, \\ London, UK; ' jDepartment of Addictive Behavior and Addiction Medicine, Central Institute for Mental Health, \\ University of Heidelberg, Medical Faculty, Mannheim, Germany
}

\section{Keywords}

Technology-based interventions · Addiction · Internet · Drug policy · European Union

\begin{abstract}
Background: Clinicians in the field of drug addiction have started to exploit the growth of Technology-Based Interventions (TBIs). However, there is little information on how health personnel evaluate them. Methods: Semi-structured interviews were conducted among 20 European experts. Results: All of the interviewees recognised TBIs as a valuable tool to improve the management of substance-use disorders (SUDs). Most interviewees indicated that combining both traditional face-to-face therapist-patient clinic appointment with TBIs is probably the most effective method. Most interviewees agree that TBIs are valuable tools to overcome both physical and social barriers, and hence significantly facilitate the access to treatment. Poor infrastructure and lack of digital lit-
\end{abstract}

\section{KARGER}

(C) 2017 S. Karger AG, Basel

E-Mail karger@karger.com

www.karger.com/ear eracy are recognised as major barriers to the diffusion of these tools. Conclusions: The application of various forms of technology in SUD treatment is an interesting development for the European Union. Technical and non-technical barriers exist and impede their full exploitation.

(c) 2017 S. Karger AG, Basel

\section{Background}

Substance-use disorders (SUDs) are major public health concerns in the European Union (EU), with considerable interpersonal, physical and societal consequences [1-3]. Researchers and clinicians in the field of drug addiction have started to exploit the exponential growth of new technologies for treatment purposes, and an increasing number of interventions have been developed [4-7]. Technology-based Interventions (TBIs) for SUDs may include computer-assisted behaviour thera- 
pies, education, prevention and information interventions (e.g., drug-use prevention, infectious diseases prevention programmes, cannabis prevention programmes), recovery support programmes and wellness monitoring of remission.

According to Barak et al. [8], TBIs are divided into four categories: (i) web-based interventions, (ii) online therapy, (iii) artificial intelligence, and (iv) other online activities. The first two categories are more developed than the rest. Web-based self-help interventions primarily consist of self-guided intervention programmes that are executed by means of a supervised online programme through a website used by clients [8]. Online counselling and therapy is a communication method (text, audio or videobased) of process-oriented guidance via the internet. Artificial intelligence and virtual therapeutic software encompass a variety of technologies such as artificial intelligence (e.g., robot simulation of therapists) and virtual reality environments. Therapeutic use of social media (e.g., blogs, Twitter, email list correspondence, online support groups and networks) are generated and maintained by users rather than clinicians but include services that are moderated by a health worker. The classification has more of a practical than a theoretical value, with each category often including aspects of other categories [8].

Despite growing evidence for efficacy of TBIs for addiction care and prevention, there is little information on how health personnel working with patients with SUDs evaluate them. In addition, barriers to using such approaches among health workers are largely unknown. Therefore, semi-structured interviews were conducted among European experts in the field of addiction treatment, aiming to explore the use of TBIs in SUDs, and to identify factors hindering the implementation of TBIs in Europe.

\section{Methods}

Respondents of the interviews were selected among members of professional organisations in the field of addiction, with consolidated experience in SUD treatment, within the European Brain Council network. The interviews were carried out by phone or via a laptop through platforms such as Skype or GoToMeeting. Interviews lasted between 30 and $60 \mathrm{~min}$. In order to be prepared, interviewees received the topics several days in advance. Interviews followed a predefined list of themes, focusing on (i) the value of TBIs for improving different aspects of SUDs (i.e., to provide care to a larger number of users, mainly outside the formal care settings; to aid people with barriers in accessing treatment; to be cost effective); (ii) factors hindering the implementation of TBIs (namely, poor infrastructure/equipment, lack of digital literacy of health workers and drug users); and (iii) actions that could help in over- coming these obstacles. Recorded interviews were examined carefully and repeatedly to acquire an overall understanding of content related to the aim of the study. The interviews were then examined again while noting down reflections and impressions (e.g., similarities and differences among participants). Each interview was divided into meaning units. Condensed meaning units were then extracted out of the existing meaning units with regard to the context. Those condensed meaning units, which were related in terms of their meaning and content, were merged into subthemes. These subthemes were then related to an overall theme.

\section{Results}

\section{Characteristics of Participants}

Overall, the invitation to participate in the interview was sent to 29 experts and 20 interviews were collected (response rate 69\%). The mean age of the sample was 52.6 (SD 10.47) and $83 \%$ were males. The majority of participants $(50 \%)$ worked in public organisations (addiction treatment centre, national/regional health governmental agency, etc.), while the rest were from the academia/research centres (40\%) and the private sector (10\%). The majority of participants included medical doctors (76\%), or specialists in psychiatry. Other categories included researchers (12\%) and psychologists (6\%). The mean number of years of experience in the field of SUDs was 23.4 (SD 9.79). Six of the respondents worked in Italy, 4 in the United Kingdom, 3 each in France and the Netherlands and 2 each in Poland and Germany.

\section{Value of TBIs in SUDs}

All of the interviewees recognised TBIs as a valuable tool to improve the management of SUDs, as revealed by this quote: "For future healthcare it is really important to move on with TBIs". However, most interviewees agreed that TBIs cannot stand alone and a combination of both traditional face-to-face therapist-patient clinic appointment and TBIs (blended interventions) is seen as the most effective method. The extent to which TBIs should be included in therapeutic programmes should always be carefully considered. The right balance between traditional face-to-face therapist-patient clinic appointment and TBIs components depends on several factors such as the age of the patient, motivation levels and the psychiatric profile of patients, among other factors.

Most interviewees said that TBIs are valuable tools to overcome both physical and social barriers for treatment, such as stigma, and hence significantly facilitate access to treatment. Moreover, several interviewees mentioned that new technologies played an important role in providing in-
Quaglio/Schellekens/Blankers/Hoch/ Karapiperis/Brand/Nutt/Kiefer 
formation, as well as in the prevention, screening and early detection of populations at risk. In this regard, TBIs, as the first-line intervention, offer a platform where people can test themselves if they have a problem and find further help, as captured in this quote: "Stand-alone TBIs are good for a broad variety of users to deliver a first baseline intervention".

Many interviewees emphasised the relevant role that TBIs could have in reducing the addiction treatment gap in the EU. This perception is captured in this statement: "You get a new group of users in the treatment, particularly young users, that otherwise would not engage". According to some interviewees, blended interventions could also improve the engagement and adherence to treatment through intensifying medical support provided to clients. Forums, social media and mobile apps linked to the treatment were specifically indicated regarding this. In particular, the effectiveness of patient-to-patient platforms controlled by physicians in facilitating access, engagement and compliance to treatment has been highlighted.

\section{Barriers for the Implementation of TBIs}

Many interviewees complained that, at present, there is limited evidence of the cost-effectiveness of e-Health solutions for SUDs. Some TBIs, like brief screening interventions for SUDs, may be cost-effective due to their relatively low setup costs. On the contrary, others, like platforms for treatment and management via the internet, require high setup and maintenance costs.

Many participants stated that they were willing to get involved in the implementation of TBIs in SUDs; however, they declared that they were not sufficiently supported by appropriate training and redesigned TBI infrastructures. Poor e-Health platforms (lack of common standards, scarce interoperability, rare integration of new and existing TBI solutions, etc.) were largely recognised as a major barrier to the diffusion of TBIs in the treatment of addiction. Interviewees emphasised the lack of national medical guidelines for digital skills, whereas all participants acknowledged the need for better digital literacy.

The majority of interviewees believed that, despite an increase in the number of studies on TBIs for SUDs, a relatively small number of them are of suitable quality. Few studies report follow-up assessments beyond 6 months after treatment, thereby limiting the knowledge about the long-term effects of these treatments. The novelty of this field has precluded the establishment of a gold standard evaluation method and this limits the extent to which studies can be compared, as revealed by this quote: "We do not have standards to evaluate the effectiveness and safety of TBI platforms". A number of interviewees considered the

Use of New Technologies in the EU for

Treating Addiction non-integration of TBIs in the formal national reimbursement system a as major hampering factor, which in turn does not stimulate either investments in this sector or the use of these technologies in clinical practice.

\section{Future Actions for the Implementation of TBIs}

Most of the interviewees emphasised that more research should be carried out, targeting the performance of these interventions especifically in the real-life context. It was noted that TBIs per se can be powerful research tools, as the patient data from TBIs provides a valuable set of real-life data immediately available for research purposes.

Integrating training programmes on TBIs in the training programmes for healthcare professionals dealing with addiction and establishing incentives promoting the development and use of TBIs in the clinical practice were considered to be ways to increase awareness of TBIs among health care professionals, as revealed by this quote: "You need to promote these services with highly resourced approaches". Some interviewees highlighted the need to increase funding and improve coordination of initiatives promoting TBIs in Europe. Collaboration between different actors including professional and patient organisations, as well as national health authorities and the private sector, should be carried out in order to avoid duplicating and overlapping and ensure the sustainability of such initiatives.

\section{Discussion}

This qualitative study aimed to explore the potential of TBIs as tools for care in SUDs and factors hindering their implementation. The interviewees recognised that new technologies are valuable tools to overcome both physical and social barriers such as stigma. Some emphasised the relevant role that new technologies could have in reducing the SUD treatment gap in the EU. Poor infrastructure and the lack of digital literacy are largely recognised as major barriers to the diffusion of TBIs.

\section{Value of TBIs in SUDs}

To fully realise the potential of TBIs, several areas of inquiry remain important. A challenge will be to understand how to integrate these new treatment modalities into traditional face-to-face therapist-patient clinic appointment treatment. The integration of these new technologies into traditional treatment facilities is probably a more feasible and effective exploitation of these tools; this may enhance the efficacy of the treatment approach as a whole, tailoring

Eur Addict Res 2017;23:177-181

DOI: $10.1159 / 000478904$ 
the treatment to the specific user's characteristics. Most interviewees believed that new technologies can be used as tools for early detection of populations at risk. TBIs can communicate through various channels outside the traditional clinical setting, including email campaigns, social media, search engines, music- and video-sharing websites, mobile advertising and applications [9].

In the EU, a considerable number of people with SUDs do not seek treatment. This means that existing treatment options are not suitable or sufficiently interesting for all subjects. Most interviewees agree that TBIs are valuable tools to overcome both physical and social barriers such as stigma, and hence facilitate the access to treatment. Europe is experiencing a high prevalence of drug use, with a low percentage of people undergoing treatment. For example, $10 \%$ or less of the people fulfilling the diagnostic criteria of alcohol-use disorders receive treatment in Europe [1]. The majority of European smokers have tried to quit (59\%) [2], but only a minimal proportion of smokers received adequate care and treatment [10]. Existing European cannabis treatment programmes reach only a very limited proportion of problematic cannabis users $[9$, 11]. An important reason of this is the prevailing stigma that has been shown to reduce the probability of approaching healthcare services $[12,13]$. TBIs appear to be recognised as useful instruments in order to reduce these gaps.

\section{Existing Barriers and Future Potential for}

Implementation of TBIs

Funding concerns among respondents can certainly be attributed to the European economic downturn and the rapidly escalating costs of healthcare systems in the EU [14]. However, funding concerns are also a consequence of the direct cost of TBIs, because it is true that the cost of hosting and maintaining access to TBIs is generally limited, but the initial development of these programmes can be expensive. More economic evaluations are certainly needed. As SUDs are chronic relapsing disorders associated with economic consequences, the societal perspective should be an integral part of this evaluation [14].

Investing in research for better understanding the potential and limits of TBIs was largely recognised by interviewees. Research is needed to investigate the differences between existing technology programmes. There may be a difference in efficacy because of the different communication methods used or because of the frequency and intensity of personal contact between the clinician and the participant. Studies should be better designed to match the characteristics of individuals with intervention modalities. Most drug treatment programmes are for lic- it drugs, but it is also important to gain data about TBIs for illicit drugs. Self-reported data should be confirmed through biochemical testing. Few studies included robust follow-up assessments [15].

A substantial portion of respondents reported the need to increase awareness about the benefits of TBIs and foster digital literacy among healthcare professionals and clients. Dissemination efforts should aim to demystify possible doubts among health professionals, such as compromised patient care, or viewing TBIs as a competitor, able to replace the health professional at work [16]. Instead, the introduction of these tools should be framed as a way to allow providers to improve the quality of their work, focusing on the most demanding issues, and reach out to a greater number of patients. The vast majority of participants felt insufficiently trained to deal with the digital revolution and the idea of establishing tailored training programmes was strongly supported. It has been noted that the EU spends many resources on e-Health implementation strategies; however, this could have little effect because the ability of health professionals to adopt this change is lacking [17]. The digital literacy that health workers need extend beyond understanding how TBIs work and include the ability to instruct patients on how TBIs can be used [18]. In fact, several studies noted a limited IT knowledge among drug users, which suggests that an effort should be made to disseminate information and apply TBIs to this population [19-20]. Finally, a concern that the interviewees expressed is the lack of adequate reimbursement for TBI services in many EU Member States. Payment and regulatory systems should be refined and adequately extended to go beyond electronic medical records and telehealth/distance-care interventions, enhancing the quality, efficiency and cost-effectiveness of care [4].

In conclusion, this survey has some limitations similar to those of other qualitative research, including difficulty to characterise findings in a visual way and bias of number of respondents. Other limitations are the limited number of EU countries represented by the respondents, with an over-representation of Southern and Western European countries, the high mean age of the sample, and lack of psychologists in a study that mainly involved psychological interventions. However, all participants were working in the field of drug addiction, and they all provided responses that reflected their long experience in SUDs. The application of various forms of technology employed to prevent and treat SUDs appears to be an interesting and promising solution among the health care professionals in the EU. However, technical and non-technical barriers exist and
180

Eur Addict Res 2017;23:177-181

DOI: $10.1159 / 000478904$
Quaglio/Schellekens/Blankers/Hoch/

Karapiperis/Brand/Nutt/Kiefer 
impede the growth of TBIs and hinder their full exploitation. Stakeholders involved in the implementation of TBIs in SUDs in the EU should be aware of the obstacles in the adoption and use of these tools among health workers.

\section{Disclaimer}

The views expressed in this publication are the sole responsibility of the authors and do not necessarily reflect the views of the affiliated organisations.

\section{Acknowledgements}

The authors wish to thank the European Psychiatric Association and the European Federation of Addiction Societies for their help in the collection of interviews. We are grateful to Amr Dawood, Scientific Foresight Unit (STOA), for his comments and suggestions while revising the manuscript.

\section{Disclosure Statement}

The authors have no conflicts of interest to disclose.

\section{Funding}

The field work for the present survey was carried out by the European Brain Council, and funded by the Directorate-General for Parliament Research Services (DG EPRS) of the European Parliament (grant number 5-0-03210-02).

\section{Authors Contribution}

G.L.Q. and G.E. contributed to the development of the study design as well as to the collection, extraction and analysis and data. A.S., M.B. and E.H. contributed to the evaluation of data. All authors contributed to the drafting of this manuscript and approved of the final version.

\section{References}

1 Rehm J, Manthey J, Struzzo P, Gual A, Wojnar $\mathrm{M}$ : Who receives treatment for alcohol use disorders in the European Union? A crosssectional representative study in primary and specialized health care. Eur Psychiatry 2015; 30:885-893.

2 European Commission (EC): World No Tobacco Day: Eurobarometer Reveals That Tobacco Use is Down by 2 Percentage Points in the EU Since 2012, but $26 \%$ of Europeans are Still Smokers. 2015, pp 39-40.

3 European Monitoring Centre for Drugs and Drug Addiction (EMCDDA): European Drug Report: Trends and Developments, 2016.

4 Marsch LA, Dallery J: Advances in the psychosocial treatment of addiction: the role of technology in the delivery of evidence-based psychosocial treatment. Psychiatr Clin North Am 2012;35:481-493.

5 Marsch LA, Carroll KM, Kiluk BD: Technology-based interventions for the treatment and recovery management of substance use disorders: a JSAT special issue. J Subst Abuse Treat 2014;46:1-4.

6 Wood SK, Eckley L, Hughes K, Hardcastle KA, Bellis MA, Schrooten J, et al: Computer-based programmes for the prevention and management of illicit recreational drug use: a systematic review. Addict Behav 2014;39:30-38.

7 Kiluk BD, Carroll KM: New developments in behavioral treatments for substance use disorders. Curr Psychiatry Rep 2013;15:420.
8 Barak A, Klein B, Proudfoot JG: Defining internet-supported therapeutic interventions. Ann Behav Med 2009;38:4-17.

9 Hoch E, Preuss UW, Ferri M, Simon R: Digital interventions for problematic cannabis users in non-clinical settings: findings from a systematic review and meta-analysis. Eur Addict Res 2016;22:233-242.

10 World Health Organization (WHO): Few Smokers Get the Help they Need. 2017. http:// www.who.int/tobacco/mpower/publications/en_tfi_mpower_brochure_o.pdf?ua $=1$ (cited June 20, 2017).

11 European Monitoring Centre for Drugs and Drug Addiction (EMCDDA): Treatment of Cannabis-Related Disorders in Europe, 2015.

12 Gates P, Copeland J, Swift W, Martin G: Barriers and facilitators to cannabis treatment. Drug Alcohol Rev 2012;31:311-319.

13 Wallhed Finn S, Bakshi AS, Andréasson S: Alcohol consumption, dependence, and treatment barriers: perceptions among nontreatment seekers with alcohol dependence. Subst Use Misuse 2014;49:762-769.

14 Donker T, Blankers M, Hedman E, Ljótsson B, Petrie K, Christensen H: Economic evaluations of internet interventions for mental health: a systematic review. Psychol Med 2015;45:3357-3376.

15 Gainsbury S, Blaszczynski A: A systematic review of internet-based therapy for the treat- ment of addictions. Clin Psychol Rev 2011;31: 490-498.

16 Ramsey A, Lord S, Torrey J, Marsch L, Lardiere M: Paving the way to successful implementation: identifying key barriers to use of technology-based therapeutic tools for behavioral health care. J Behav Health Serv Res 2016;43:54-70.

17 European Health Parliament. Digital Skills for Health Professionals. Committee on Digital Skills for Health Professionals. 2016. http://www.healthparliament.eu/documents/10184/0/EHP_PAPERS_2016_DigitalSkillsForHealthProfessionals_SCHERM. pdf/e 07 b 23 d 9 - e $762-4$ f $96-934$ b d23e6c5d17af (cited June 20, 2017).

18 King VL, Stoller KB, Kidorf M, Kindbom K, Hursh S, Brady T, et al: Assessing the effectiveness of an Internet-based videoconferencing platform for delivering intensified substance abuse counseling. J Subst Abuse Treat 2009;36:331-338.

19 VanDeMark NR, Burrell NR, Lamendola WF, Hoich CA, Berg NP, Medina E: An exploratory study of engagement in a technologysupported substance abuse intervention. Subst Abuse Treat Prev Policy 2010;5:10.

20 McClure EA, Acquavita SP, Harding E, Stitzer ML: Utilization of communication technology by patients enrolled in substance abuse treatment. Drug Alcohol Depend 2013;129: 145-150.
Use of New Technologies in the EU for Treating Addiction
Eur Addict Res 2017;23:177-181 DOI: $10.1159 / 000478904$ 